Published in "Applied Economics", 2019, vol. 51, no. 30, pp. 3236-3255, which should be cited to refer to this work.

DOI : $10.1080 / 00036846.2019 .1566686$

\title{
Behavioural Heterogeneity in Wine Investments ${ }^{\dagger}$
}

\author{
Adrian Fernandez-Perez ${ }^{\mathrm{a},}{ }^{*}$ \\ Bart Frijns ${ }^{\mathrm{a}}$ \\ Alireza Tourani-Rad ${ }^{\mathrm{a}}$ \\ Jean-Philippe Weisskopf ${ }^{\mathrm{b}}$
}

This Version: September 2018

\begin{abstract}
We introduce a heterogeneous agent model to explain the dynamics of fine wine investments. Our results show evidence of the existence of both fundamentalists - those who trade on mean-reversion towards a fair value - and chartists - those who extrapolate recently observed price trends - in the wine market. Moreover, we document that market participants switch between the two trading strategies, allocating more weight to the strategy that has been the most accurate in forecasting wine index values in the recent past. This switching behaviour can explain the large variations in index values (bubbles and crashes) that are observed in the fine wine market.
\end{abstract}

JEL Codes: C22; G11.

Key Words: Wine Investments, Heterogeneous Agent Models, Behavioural Finance.

\footnotetext{
aAuckland University of Technology, Private Bag 92006, 1142 Auckland, New Zealand.

${ }^{b}$ Ecole hôtelière de Lausanne, HES-SO // University of Applied Sciences Western Switzerland, Route de Cojonnex 18, 1000 Lausanne, Switzerland. \& Bordeaux Wine Economics.

${ }^{\dagger}$ We would like to thank the editor and the referees for their useful suggestions. We would also like to thank the participants at the 2017 Annual AAWE Meetings (Padova, Italy) for their useful comments and suggestions. We would like to thank Liv-Ex for providing us with regional index and constituent data.
} 


\section{Introduction}

“The emotional and social attachment to treasure means that investors are extremely likely to make sub-optimal decisions about when to buy, sell or how much to pay." (Mitchell, 2012)

Collectibles as an asset class have received considerable attention in recent years. On average, high net-worth individuals hold nearly $6 \%$ of their assets in collectibles (see Knight Frank, 2017). Being a significant asset class, many studies have looked at the benefits of collectibles in a portfolio of financial assets (see e.g., Worthington and Higgs, 2004; Veld and Veld-Merkoulova, 2007; Campbell, 2008; Dimson and Spaenjers, 2014; Korteweg, Kräusl and, Verwijmeren, 2015). Others have made more direct comparisons with traditional financial assets and examined the risk-return characteristics of a variety of collectibles (e.g. Hiraki, Ito, Spieth and Takezawa, 2009; Dimson and Spaenjers, 2011; Dimson, Rousseau and Spaenjers, 2015; Coslor and Spaenjers, 2016; Martin, 2016). However, collectibles are also known to be affected by emotions, and are thus often referred to as emotional assets. This emotional aspect is shown to affect prices of collectibles (see Renneboog and Spaenjers, 2013), and can lead to speculative bubbles (e.g. Penasse and Renneboog, 2017; Kräussl, Lehnert and Martelin, 2016).

While much of the literature on bubble behaviour in collectibles has focused on art, another important collectible, fine wine, has received less attention in this regard. There is a growing interest in wine as an investment asset, ${ }^{1}$ with more than $37 \%$ of high net-worth individuals around the world having invested in luxury goods such as fine

${ }^{1}$ According to Wine Spectator sales at major wine auctions increased from 90 million USD in 2002 to 381 million USD in 2017. 
wine (see Knight Frank, 2017). One common argument for investing in wine is that it provides diversification benefits, due to its relatively low correlations with financial assets (e.g. Sanning et al., 2008; Masset and Henderson, 2010; and Masset and Weisskopf, 2018a). ${ }^{2}$ In addition, investments in wine produce attractive returns that are well in excess of government bonds (Dimson et al., 2015). ${ }^{3}$ As a consequence, in recent years, we have seen the introduction of several Wine Funds (see e.g. Lucey and Devine, 2015) as well as the creation of several Wine Indices (e.g. the indices developed by Liv$\left.\mathrm{Ex}^{4}\right)$

But wine is also an emotional asset (such as art, vintage cars, rare stamps or historical coins), where market participants not only invest to pursue financial goals but also for the enjoyment they derive from it. This emotional aspect of wine can lead to bubble-like behaviour (Czupryna and Oleksy, 2015; Dimson et al., 2015; Jovanovic, 2013), as emotions can lead to irrational behaviours such as herding, and can cause prices to deviate from their fair value over prolonged periods of time. This, for instance, has been witnessed in the wine market in $2011 .^{5}$

Another feature of wine investments is that deviations from intrinsic values cannot be arbitraged away due to market illiquidity, high transaction costs (storage, shipping, insurance, auction premia) and information asymmetries. More importantly, price differences can emanate from a base of heterogeneous customers (Häberle and Masset, 2016; Cardebat et al., 2016) who may trade in wine for different reasons

${ }^{2}$ This low correlation with financial assets should be put in perspective as investing in fine wine is not as liquid as investing in traditional financial assets (Masset and Weisskopf, 2018b).

${ }^{3}$ Dimson et al. (2015) document a return of $10.9 \%$ p.a. over the period $1900-2012$, compared with a $6.1 \%$ return p.a. on US government bonds.

${ }^{4}$ London International Vintners Exchange (www.liv-ex.com).

${ }^{5}$ See for instance http://www.winespectator.com/webfeature/show/id/46287. However, this bubble-like behavior has been recognized earlier. For instance, Robinson (1998) notes that: "What is more extraordinary is the wild price variation at the very top end -fine wines. Demand bubbles up mysteriously, apparently fuelled by fashion and rumour as much as by intrinsic quality". We further note that bubble-like behaviour is also observed in other markets for emotional assets, such as the art market (see e.g. Kräussl et al. 2016 or Penasse and Renneboog, 2017). 
(collection, investment, speculation or consumption) causing different price triggers based on their knowledge about fair values, access to information or beliefs of the future evolution of the market. Since the presence of these different types of investors could expose the wine market to extreme prices, understanding the behaviour of different types of investors in the wine market is of considerable importance.

The objective of this paper is to examine the dynamics, and bubble-like behaviour, on the market for fine wine by applying a heterogeneous agent model (HAM). ${ }^{6}$ Using this model, we aim to assess whether there is evidence of behavioural heterogeneity in this market, and whether this behavioural heterogeneity can explain the dynamics that we observe in the market for fine wine. A HAM assumes that a market is populated with investors who form beliefs about the future value of an asset based on different strategies and switch between these different beliefs on signals they obtain from the past performance of their trading strategies. The model assumes that investors generally have two types of beliefs. The first belief is often referred to as fundamentalism, and is a belief in mean-reversion of prices towards a level which seems to represent a fair value. The HAM literature refers to this fair value as the fundamental value. Although we acknowledge that the concept of a fundamental value for wine is rather moot as wine investments do not generate cash flows, one should take this concept in a generic manner and interpret it as a fair price. If we believe that the price of wine reflects common attributes such as quality (vintages and producers), individual and collective reputation and natural endowments (producer) as shown in numerous studies on wine price determinants (see, e.g., Oczkowski and Doucouliagos (2014) for a review of this literature), then one could define a fair price as a reflection of the longrun average growth rate in the price of wine. The second belief is referred to as chartism

\footnotetext{
${ }^{6}$ Although it is not the purpose of this paper to assess bubbles in the context of Phillips et al. (2011, 2015), in unreported tests, we find that there are indeed episodes with explosive behaviour in our wine index. These results are available on request.
} 
or trend-following, a belief that recent trends in the market can be extrapolated into the future.

We assess bubble-like behaviour in the fine wine market by considering the deviations from its fair value. Theoretically, a speculative bubble appears when the dynamics of an asset cannot be explained by either the rent, asset and product cycle. Since wine does not provide any cash flows only the asset and product cycles are relevant. When we define a specification for the fair value, we capture the asset cycle by time trends (and in further robustness tests use time polynomials and moving averages as alternatives) and capture the product cycle through the inclusion of vintage dummies. ${ }^{7}$ While it is our aim to describe the bubble-like behaviour in the fine wine market, we are not necessarily modelling the behaviour of emotional and non-emotional investors. Rather, we would argue that emotional behaviour can lead to deviations from fair values (due to irrationality, manifesting itself e.g. through herd behaviour) that traders can exploit by either following a chartist strategy or a fundamentalist strategy (see the model section for more detail).

We implement the HAM to explain the dynamics of the Liv-Ex Fine Wine Investables Index which tracks the most investable wines in the fine wine market, and find significant evidence for the existence of both types of traders in this market. ${ }^{8}$ Moreover, we find evidence of significant switching behaviour between fundamentalist and chartist beliefs, where investors follow the belief that has been the most accurate in forecasting prices in the recent past. $^{9}$ This switching behaviour can explain index deviations from fair values observed in the fine wine market. Specifically, we document

\footnotetext{
${ }^{7}$ We thank the referee for pointing this out to us.

${ }^{8}$ Note that throughout the paper we use the terms "index value" and "price" interchangeably. Where we use the term "price" in the context of our analysis, we essentially refer to index values.

${ }^{9}$ This switching behavior can be interpreted in two ways. Either investors change their beliefs and instead of following one strategy decide to follow another strategy, or there is heterogeneity among investors, and investors with different beliefs (e.g. investors, consumers and collectors) choose to trade at different times when they realize that their trading strategy is more accurate.
} 
that any large positive or negative deviations from fair values coincide with the majority of investors trading on the basis of a chartist belief. Further robustness testing reveals that our results do not hinge on the particular model we use to define the fair value as our results hold using alternative specifications. This alleviates any concerns about the precise definition of a fair value of wine as its definition does not appear to impact our findings.

We further refine and extend our analysis to a set of Liv-Ex indices covering several distinct winegrowing regions from across the world, and document that the heterogeneity in beliefs of investors is strongest for the Liv-Ex Fine Wine Investables Index. This result is expected as Bordeaux wines - which are the constituents of the LivEx Fine Wine Investables Index - are the best-known wines and are most prone to speculative investing due to their status and emotional value. This index also tends to display the highest heterogeneity in terms of market participants as compared to smaller, more complex regions analysed (such as Rhone or Italian wines). Overall, our model and results provide an explanation for bubble and crash behaviour in fine wine prices and the observed high volatility in wine as documented by Dimson et al. (2015).

Our findings contribute to the literature in several ways. To the best of our knowledge, we are the first to implement a HAM on collectables, in general, and the wine market, in particular. This model appears especially useful to study and explain the dynamics of the fine wines values in the presence of diverse clients with different beliefs and informational characteristics. While some papers have looked into the pricing of fine wine (Oczkowski and Doucouliagos, 2014) and its benefits as an asset class (Storchmann, 2012), the importance of segmentation and the accompanying effect this may have on the price dynamics of the wine market has not received due attention. Furthermore, the use of wine indices covering multiple wine-growing regions in which 
different customer segments operate deepens our analysis. The application of our model clearly demonstrates that it is especially those sub-markets in which investors and/or speculators are active that display the highest heterogeneity and switching behaviour. Market segments for which price information is less readily available display a more homogenous behaviour. In addition, our paper contributes to the explanation of bubblelike behaviour in the fine wine prices. The presence of a bubble-like evolution in the Bordeaux and especially Lafite market has been put forward by practitioners (Serdarevic, 2012) and pointed out by academics (Masset and Weisskopf, 2016) but its existence or creation has not been investigated empirically.

The remainder of this paper is structured as follows. In Section 2, we discuss some of the related literature. In Section 3, we develop a heterogeneous agent model that allows for traders with different beliefs to be present in the market. In Section 4, we discuss our data. Section 5 discusses empirical results and highlights some of the implications of the model in terms of switching behaviour and the occurrence of bubbles and crashes. Finally, Section 6 concludes.

\section{Literature}

In this Section, we first review some of the relevant literature related to investments in wine. Subsequently, we discuss the heterogeneous agent model literature.

\subsection{Wine Investments}

Several studies have analysed the potential of fine wine as an investment (e.g. Faye et al., 2015; Masset and Henderson, 2010; Masset and Weisskopf, 2018a; Burton and 
Jacobsen, 2001; Dimson et al., 2015; Sanning et al., 2008) or studied the determinants of wine prices. ${ }^{10}$

Previous research has tried to model the price of fine wine and has found several characteristics that explain, at least partly, the value of a specific bottle of wine. These include natural features such as the soil (terroir) (Gergaud and Ginsburgh, 2008) and especially the climate (Ashenfelter, 2010). This dimension is complemented by features which are specific to the respective producer, such as the winemaking techniques but also to the history and reputation of a producer (Hadj Ali and Nauges, 2007). All of this will have an effect on the aging potential and quality of the specific wine. Finally, the adherence to an appellation or a region also has some influence (Cardebat and Figuet, 2004). From a more macroeconomic viewpoint the overall economic situation (Masset and Weisskopf, 2018) or adverse FX movements (Jiao, 2017) have an effect on consumer spending and thus on the price customers are willing to pay for a bottle of fine wine. Overall, wine prices are thus driven by the quality of a wine, the individual and collective status of a producer and the economic environment.

These more objective criteria are able to explain a good proportion of fundamental wine prices. However, another proportion is less tangible and remains more difficult to quantify. It is related to the intrinsic behaviour of customers who may behave emotionally and therefore may either drive prices away from their fundamental value or lead producers to adapt their pricing strategy. More recent literature has started to study this part by looking into client segmentation which may display diverging behaviour and draw different utility functions out of a bottle of fine wine (Cardebat et al., 2017). Other studies examine the effects of marketing tools on the purchase

\footnotetext{
${ }^{10}$ See Oczkowski and Doucouliagos (2014) for a recent survey on wine price determinants.
} 
behaviour of customers and how these lead to a differentiated willingness to pay (Danner et al., 2016).

While there is still no consensus about the exact definition of the intrinsic value for fine wine, we have a good understanding of the drivers of fine wine prices. However, studies on fine wine also call for a more thorough examination of the price dynamics underlying this market. While fine wine prices can be reasonably well described through hedonic models (Rosen, 1974), price dispersion and deviations are more difficult to explain. Fine wines are emotional assets whose prices are formed by factors unique to each investor. A common feature of such an asset is the existence of an emotional premium that an investor is willing to pay to capture the emotional wealth expected to arise from its holding.

A few studies have looked into price dispersion and deviations from the law of one price, and as an extension, at the segmentation of the wine market. For instance, Jaeger and Storchmann (2011) analyse wine price dispersion across retail outlets in the US and find that deviations from the law of one price are common. They indicate even stronger deviations for the high-priced wines due, amongst others, to diverging state regulations. This evidence is complemented by Cardebat et al. (2014) in a study on the role of wine experts who state that the law of one price very often fails to hold, especially if experience goods, ${ }^{11}$ such as fine wines, are involved.

Häberle and Masset (2016) classify wine market participants into four distinct categories: investors, collectors, inexperienced buyers and wine lovers. They show that different wine regions and types will attract different buyers and thus lead to a segmentation of the wine market potentially generating differing price dynamics comparable to evidence from traditional financial markets. Similarly, Cardebat et al.

\footnotetext{
${ }^{11}$ Wine can be considered a prime example of an experience good as a consumer can only elicit its true intrinsic quality once purchased and consumed.
} 
(2016) look at the drivers of price dispersion in the wine auction market based on taxonomic theory and the presence of heterogeneous agents. They suggest that different agents (investors, collectors and consumers) in the wine market display diverging attributes and goals. Finally, Masset et al. (2016) show indirect evidence of a geographical segmentation of the market with Asian buyers paying a premium of up to $60 \%$ at Hong Kong wine auctions as opposed to wine proposed at non-Asian auction locations.

Research on the existence of price bubbles in the wine market is scarce. Some studies have examined the efficiency of the wine market which can indirectly be associated to bubble creation. Masset and Henderson (2010), for instance, cannot reject the hypothesis of a unit root in a portfolio that invests in fine wines. Erdős and Ormos (2013) use more advanced and diverse techniques to perform an in-depth study of weakform efficiency of the wine market. Initial results confirm those of Masset and Henderson (2010), i.e. the wine market does not appear to be efficient. However, their study suggests that fine wine has a stationary and random walk component leading to positive auto-correlations. Finally, Bouri et al. (2016), accounting for shifts and breaks in wine price data, conclude that the wine market is inefficient.

As mentioned before, the emotional aspect and inefficiency of fine wine makes it prone to bubble-like behaviour (Czupryna and Oleksy, 2015; Dimson et al., 2015; Jovanovic, 2013). That is, a fine wine, as a non-reproducible and exhaustible commodity with strong emotional charge, seems to be vulnerable to exaggerated upward price movements, which, together with the impossibility of short selling, can lead to the emergence of speculative bubbles. In a traditional sense, such bubbles occur when prices strongly deviate from their intrinsic value over a prolonged period of time. 
Wine prices, being subject to both rational and irrational factors, can thus fluctuate widely leading to price bubbles and busts.

While current research does not allow us to exactly define the intrinsic value for fine wine, the wine literature does let us identify the drivers of fine wine prices. We also know that customer segmentation and the behavioral aspect of wine market participants has an impact on the wine market. This article therefore wants to build on these findings by examining how the time-varying activity of different market participants present on the wine market may explain wine price dynamics.

\subsection{Heterogeneous agent models and bubble-like behaviour}

One approach taken in the literature to model bubble-like behaviour in financial assets is that of heterogeneous agent models, with one of the seminal papers in this area by Brock and Hommes (1997). In that paper, the authors introduce a heterogeneous agent model (HAM), where agents can choose between an inferior, but free forecaster of the price of an asset versus a superior forecaster that comes at a small cost. Brock and Hommes (1997) demonstrate that the presence of a small cost to the superior forecaster and a high sensitivity to relative past profits based on the different forecasters can lead to price dynamics that can explain bubble and crash scenarios. Brock and Hommes (1998) extend their original model to a setting of financial markets, and define concepts of fundamentalist beliefs - investors who believe in mean-reversion in the price of an asset to its fundamental value - and chartist beliefs - investors who believe in extrapolation of recently observed price patterns. Brock and Hommes (1998) demonstrate, through numerical simulations, the existence of both types of beliefs and

trading strategies that are sensitive to the past profitability of the different beliefs leading to bubbles and crashes in financial markets. 
The above mentioned papers, being purely theoretical in nature, use simulations to demonstrate the interesting dynamics that can be generated by these HAMs, such as bubbles, crashes, and excess volatility. The first empirical estimation of a HAM was carried out by De Grauwe and Grimaldi (2005a) who develop an empirical specification based on the existence of fundamentalists and chartists to explain the dynamics of exchange rates. ${ }^{12}$ This model does not allow traders to switch between trading rules, but the authors use this model to demonstrate how such a simple specification can explain some of the empirical puzzles related to exchange rate movements. De Grauwe and Grimaldi (2005b) extend this model by allowing traders to switch between trading rules using a discrete choice framework similar to Brock and Hommes (1998). Finally, De Grauwe and Grimaldi (2006) further extend this model for exchange rates by including the impact behavioural heterogeneity has on exchange rate volatility.

Boswijk et al. (2007) derive an empirical specification of the Brock and Hommes (1998) model and estimate this model to explain the dynamics of the S\&P500 over the period 1871 to 2003. The authors demonstrate the existence of both fundamentalist and chartist beliefs in the stock market, and find that investors switch between these beliefs based on the past profitability of either the fundamentalist or chartist belief.

Following these initial empirical papers, studies have applied HAMs to explain the dynamics of various assets. For instance, Ter Ellen and Zwinkels (2010) use a HAM to explain the dynamics of oil prices while Baur and Glover (2014) use a HAM to explain the dynamics of gold prices. Similar to fine wine, both commodities do not produce cash-flows, and thus, depend on supply and demand in its purest sense. Likewise, Kouwenberg and Zwinkels (2014) implement a HAM to model the price

\footnotetext{
${ }^{12}$ Other empirical frameworks that consider fundamentalists-chartists have been considered in the literature, such as Westerhoff and Reitz (2003) and Menkhoff et al. (2009) who look at the impact of fundamentalist/chartist beliefs on the dynamics of exchange rates.
} 
dynamics of US real estate prices. These studies provide strong empirical evidence of heterogeneity in beliefs and switching behaviour based on past forecasting performance of the different beliefs. ${ }^{13,14}$

A key feature of the empirical application of HAMs is that these models can capture substantially more of the dynamics observed in assets compared with traditional linear models. HAMs can do this in very parsimonious ways, often by including only a single additional. Given that there is evidence of bubble and crash behaviour in the prices of fine wines and different types of agents that are active in this market, a HAM is wellsuited to explain the price dynamics of fine wines.

\section{Methodology}

In this section, we develop a heterogeneous agent model (HAM) to capture the dynamics of changes in the value of a fine wine index. This model builds on the theoretical works of Brock and Hommes (1997; 1998), and has close similarities to the empirical works of Ter Ellen and Zwinkels (2010), and Kouwenberg and Zwinkels (2014). Specifically, we assume that the market for fine wine has two distinct types of

\footnotetext{
${ }^{13}$ Chen et al. (2012) provide an excellent overview on the empirical HAM literature.

${ }^{14}$ Several competing approaches used to detect bubble-like behaviour have been employed on tangible or alternative asset classes. A common method is the superior-ADF (SADF) test of Phillips, Wu, and Yu (2011). For instance, Gilbert (2010) applies the SADF procedure to three CBOT future prices, wheat, corn and soybeans, concluding that during the commodity boom and bust of 2007-2008 there was explosive behaviour in soybean future prices. Phillips et al.'s SADF test is also used by Etienne et al. (2014). They find that there are speculative bubbles in 12 agricultural markets. More in line with our study, Czuprina and Olesksy (2015) find explosive behaviour in the Liv-ex 50 index. Figuerola-Ferretti et al. (2015) use a multi-bubble generalization of the SADF test, GSADF, proposed by Phillips, Shi and Yu (2015) to examine the price behaviour of the six main London Metal Exchange non-ferrous metals prices. They detect periods of mild explosivity in copper, nickel, lead, zinc and tin, but not in aluminium. Similarly, Tsvetanov et al. (2016) apply the GSADF test to crude oil prices, finding significant bubble periods. Alternative bubble detection methodologies have also been used, such as Zhou and Sornette's (2009) D-test (oil price in Zhang and Yao, 2016); van Norden and Schaller's (1993) switching regression model (grains, softs, animals and woods, precious metals, and energy in Brooks et al., 2015); or the momentum threshold autoregressive (MTAR) approach (US corn, soybean and wheat prices) of Adämmer and Bohl (2015).
} 
investors: speculators who trade in fine wine purely for their potential financial gains; and collectors/consumers, who buy fine wine for non-financial benefits they derive from owning the wine.

Within the group of speculators, we assume that investors can follow two strategies: a so-called fundamentalist strategy, where, based on market experience, information and knowledge investors expect mean-reversion of wine values towards a fair value. The second strategy considered in our HAM is a trend-chasing strategy, where investors believe in continuations of recently observed price trends (investors who follow this belief are often referred to as chartists as they look at price charts and extrapolate from those). ${ }^{15}$

More formally, we can specify the beliefs of the different types of investors (fundamentalists or chartists) in terms of their expectations about the value of wine. For fundamentalists, who rely on mean-reversion towards a fundamental value, we can specify their expectation of the future price index value as follows

$$
E_{t}^{F}\left(P_{t+1}\right)=P_{t}+\alpha\left(P_{t}-V_{t}\right)
$$

where $E_{t}^{F}\left(P_{t+1}\right)$ is the expectation that is formed at time $t$ about the value of the wine index at time $t+1$ by the fundamentalists, $P_{t}$ is the current value of the wine index and $V_{t}$ is its fundamental value. The coefficient $\alpha$ captures the degree of mean-reversion that the fundamentalist expects to occur, and is expected to be between 0 and -1 . If $\alpha=0$, then fundamentalists expect to see no mean-reversion towards the fundamental value, whereas if $\alpha=-1$, fundamentalists expect the value of the wine index to mean-revert fully towards the fundamental value in the next period. Any value of $\alpha$ between 0 and -1

\footnotetext{
${ }^{15}$ Of course, collectors and consumers may also behave as speculators, or their demand can be random as captured by the noise term in Equation (7).
} 
indicates a gradual mean-reversion of the value of the wine index towards its fundamental value.

The second group of investors, whose belief relies on the extrapolation of recent price patterns, can be formalized as follows,

$$
E_{t}^{C}\left(P_{t+1}\right)=P_{t}+\beta \sum_{l=1}^{L}\left(P_{t-l+1}-P_{t-l}\right),
$$

where $E_{t}^{C}\left(P_{t+1}\right)$ is the expectation that is formed at time $t$ about the value of the wine index at time $t+1$ by the chartists, $\beta$ is the autoregressive coefficient, and $L$ is the total number of lags that the chartists look back. $\left(P_{t-l+1}-P_{t-l}\right)$ captures the change in the value of the wine index over the lagged period, $l$. A positive coefficient for $\beta$ implies that chartists extrapolate the pattern they observed in the recent past, and that they trade on the expectation of momentum (i.e. index values will continue in the direction recently observed). A negative value for $\beta$ implies that chartists expect index values to move in the opposite direction of what has recently been observed and is in line with a so-called contrarian belief, where investors buy an asset because it has decreased in value and therefore is relatively cheap.

With these two different beliefs, fundamentalism and chartism, we can move towards the development of a model that can explain the overall dynamics of the wine index we consider. If we denote $w_{t}^{F}$ as the proportion of wine investors with a fundamentalist belief and $w_{t}^{C}=1-w_{t}^{F}$ as the proportion of wine investors with a chartist belief, we can write the expectation at time $t$ of the price of wine at time $t+1$ as, 


$$
E_{t}\left(P_{t+1}\right)=w_{t}^{F}\left(P_{t}+\alpha\left(P_{t}-V_{t}\right)\right)+\left(1-w_{t}^{F}\right)\left(P_{t}+\beta \sum_{l=1}^{L}\left(P_{t-l+1}-P_{t-l}\right)\right),
$$

where the first term on the right-hand side reflects the beliefs of the fundamentalist, and the second term the beliefs of the chartists. Thus, the expectation of the future value of the wine index is a weighted average of the different beliefs that the investors may have about its value.

A key feature of a HAM is that the weights on the fundamentalist and chartist strategies can vary over time. The HAM literature defines a specific form in which these weights evolve. Specifically, the HAM literature assumes that the dynamics in weights are driven by the past profitability or accuracy of a specific belief. For instance, if a fundamentalist belief as an investment strategy has led to superior performance, then agents who are following a chartist belief may change their investment strategy, and start to follow a fundamentalist belief. Vice versa, a relatively better performance of a chartist strategy may entice fundamentalists to become chartists. Thus, depending on the past performance of the different investment beliefs, investors may switch from one belief to another. ${ }^{16}$ This particular aspect introduces time variation in the weights, $w_{t}^{F}$ and $w_{t}^{C}$, which may lead to additional dynamics in the value of the wine index.

To formalize the evolution of weights on the specific investment beliefs, we follow Kouwenberg and Zwinkels (2014) by considering the relative forecast accuracy of the different investment strategies. Specifically, we define the forecast accuracy as the absolute forecast error, i.e.,

\footnotetext{
${ }^{16}$ Alternatively, there may be heterogeneity between investors, and specific types of investors may trade at different points in time depending on how well their strategy performs.
} 


$$
Z_{t}^{F}=\sum_{k=1}^{K}\left|E_{t-k}^{F}\left(P_{t-k+1}\right)-P_{t-k+1}\right|, \quad Z_{t}^{C}=\sum_{k=1}^{K}\left|E_{t-k}^{C}\left(P_{t-k+1}\right)-P_{t-k+1}\right|,
$$

where $Z_{t}^{F}$ and $Z_{t}^{C}$ are the forecast accuracies of the fundamentalist and chartist beliefs, respectively, and $K$ captures the number of periods that investors look back to examine the forecast accuracy of their specific trading rule.

Investors are allowed to switch between the different beliefs depending on the relative performance of one belief versus the other. To model the switching behaviour of the investors, we follow the original works of Brock and Hommes $(1997,1998)$, where the switching behaviour is modelled according to a multinomial switching function (see Manski and McFadden (1981)), but implement this function by looking at relative forecast errors as in Kouwenberg and Zwinkels (2014). Specifically, we define the weights on the fundamentalist strategy as

$$
w_{t}^{F}=\left[1+\exp \left(\gamma\left\{\frac{Z_{t}^{F}-Z_{t}^{C}}{Z_{t}^{F}+Z_{t}^{C}}\right\}\right)\right]^{-1},
$$

where $\gamma$ is the so-called intensity of choice parameter. This switching function has some desirable features that makes it attractive for the inclusion in an empirical heterogeneous agent model. First, the function specified in Equation (5) is bound between 0 and 1, which is the permissible range for weights on the fundamentalist strategy. By definition, $w_{t}^{C}=1-w_{t}^{F}$, so $w_{t}^{C}$ is also bounded between 0 and 1 , thus no additional restrictions need to be imposed on the weights of the chartists.

The intensity of choice parameter, $\gamma$, captures the degree of switching behaviour of investors and measures how sensitive the switching behaviour is with regards to past 
forecast accuracy of the specific belief. If $\gamma=0$, agents are completely insensitive to past forecast accuracy of the trading rules and do not switch between the different beliefs. If $|\gamma| \rightarrow \infty$, agents are infinitely sensitive to past relative performance of the different beliefs and switch immediately and fully between the different beliefs. If $\gamma>0$, agents switch towards the beliefs that had the best performance in the recent past, while if $\gamma<0$ agents switch away from the belief that had the best performance in the recent past (perhaps based on a belief that there is some degree of mean-reversion).

With these definitions of forecast errors and weights on the different beliefs, we can complete the specification of the dynamics of the fine wine index values. Specifically, we can rewrite Equation (3) in terms of expected returns, i.e.,

$$
E_{t}\left(R_{t+1}\right)=w_{t}^{F}\left(\alpha\left(P_{t}-V_{t}\right)\right)+\left(1-w_{t}^{F}\right)\left(\beta \sum_{l=1}^{L}\left(R_{t-l+1}\right)\right),
$$

where the return, $R_{t+1} \equiv\left(P_{t+1}-P_{t}\right) .{ }^{17}$ We can further take this specification from expectations into realization, by adding a drift and a noise term, $\varepsilon_{t+1}$, to Equation (6), i.e.,

$$
R_{t+1}=c+w_{t}^{F}\left(\alpha\left(P_{t}-V_{t}\right)\right)+\left(1-w_{t}^{F}\right)\left(\beta \sum_{l=1}^{L}\left(R_{t-l+1}\right)\right)+\varepsilon_{t+1}
$$

One can think of this noise term as representing liquidity demand, i.e. consumers or collectors whose demand for fine wines may affect prices due to consumption.

\footnotetext{
${ }^{17}$ Note that in the empirical estimation we use logs of index values and so $R_{t}$ is the continuously compounded return.
} 
Equations (7), (4) and (5) represent the HAM that we estimate empirically by QuasiMaximum Likelihood. ${ }^{18}$

\section{Data}

In this Section, we provide details of the data used in the main part of our analysis, i.e., the Liv-Ex Fine Wine Investables Index. Subsequently, we detail how we define the “fundamental value" for this index.

\subsection{Liv-ex and the Liv-Ex Fine Wine Investables Index}

Liv-ex, a London-based company, has established itself as the premier source for information on the fine wine market with the construction and communication of a multitude of wine indices, reports and blog entries. Today, the indices are used as the natural benchmark for wine market studies in practice and academia (Cevik-Sedik, 2014; Qiao et al., 2014) and are reported both on Bloomberg and Thomson Reuters DataStream. According to Masset and Weisskopf (2018b) and the Liv-ex website, the indices are calculated following a composite index approach (i.e. the same as for most stock indices) and are available for the general wine market, the Bordeaux market and other important wine-growing regions. All indices are updated on a monthly basis apart from the Fine Wine 50 which is updated daily. The exact calculation of the indices is proprietary information, but the methodology followed is clearly outlined and is complemented by information on the wines tracked, the weights allocated to the different wines and the rules of inclusion and exclusion. These follow generic rules (e.g.

\footnotetext{
${ }^{18}$ Equations (4), (5) and (7) can be combined into a single (non-linear) equation and estimated directly using quasi-maximum likelihood. This is possible as Equation (7) is a non-linear polynomial of $R_{t+1}$, with the fundamental price $V_{t}$ given as an exogenous variable (see Kouwenberg and Zwinkels, 2014).
} 
on the wine region, entry and exit dates, etc.) but are ultimately dependent on a selection committee composed of experts who review the indices on a quarterly basis. Compared to other index providers this can be considered as a very transparent approach which allows wine market participants to track and replicate indices even though it is currently not possible to directly invest in them through an ETF-type instrument.

The Liv-Ex Fine Wine Investables Index tracks the most "investable" wines in the market. It includes 200 single wines representing bottles from different vintages from the 24 top Bordeaux chateaux. The inclusion of a wine in the index follows a twostep process. To be considered in the index, a wine must be produced by one of the 24 top Bordeaux chateaux, and further, have scored at least 95-points from a leading expert (Robert Parker). The top eight Bordeaux Châteaux - the five First Growths from the Médoc, Ausone, Cheval Blanc and Petrus - can be included on the basis of a score of 93-points or above. The constituent wines are then chosen on a quarterly basis based on the evaluation of a panel of wine experts and the trade values on the Liv-ex trading platform. This ensures that only wines meeting a minimal quality and liquidity criterion are included to reach the ultimate goal of the index which is to replicate a typical wine investment portfolio. $^{19}$

Once the component wines are chosen, Liv-Ex makes use of their trading platform to price each wine. According to Liv-ex, the index uses the Mid-Price between the current highest bid and lowest offer price on the Liv-Ex trading platform. If there has been a transaction on Liv-Ex within the last 30 days and the transaction price sits within the bid-offer spread, then that price is used as the Mid-Price. Once the price of each component wine is calculated, Liv-Ex builds the index based on a price-weighted

\footnotetext{
${ }^{19}$ Portfolio constituents as at the end of our sample period are shown in Appendix A.
} 
scheme. They also apply a scarcity weighting to vintages older than 15 years, adjusting these weights to account for the low average production levels of certain fine wines (as in the weightings of Petrus and Ausone). This scarcity weighting procedure controls for consumption and production levels of the portfolio constituents. For the empirical analysis, we obtain monthly data for this index from Thomson Reuters DataStream from its inception date January 1988 to October 2016.

In Table 1, we report statistics for the levels and log returns of the Liv-Ex Fine Wine Investables Index. The index level obtained its minimum value at the beginning of the sample in January 1988 and its maximum of 369.81 value in June 2011. The index levels exhibit positive skewness and negative excess kurtosis, and the null hypothesis of normality is rejected by the Jarque-Bera test. In the last column of Table 1, we report the statistics for the monthly returns. The index has an annualized mean return of $10.30 \%$ and annualized standard deviation of $10.44 \%$. Finally, the monthly returns exhibit positive first-order autocorrelation.

\section{Insert Table 1 here}

\subsection{Calculation of the fundamental value}

Although it is not obvious how to define a fundamental or intrinsic value of wine (as an investment in wine does not generate cash flows over time), there is a general agreement that the price of wine to some extent should reflect its pedigree and vintage condition (see, e.g., Oczkowski and Doucouliagos, 2014). In defining a fundamental value, we therefore follow a very agnostic approach. Specifically, given that the index is built to mirror the performance of a typical wine investment portfolio, we use a model 
inspired by the literature on hedonic pricing models to determine the fundamental price. ${ }^{20}$ These models essentially state that in the long-run, on average, the price is a fair reflection of its characteristics, such as quality dependent on producer and vintage. We follow the wine economics literature (Ashenfelter et al., 1995; Di Vittorio and Ginsburgh, 1996; Dimson et al., 2015) and include two components: (1) a constant plus a trend component which captures the aging effect of the index; and (2) a vintage dummy which captures fixed effects related to the vintage of the component wines (e.g. production levels, weather). We run the following OLS regression for the full sample,

$$
\log \left(\text { Wine_Index }_{t}\right)=\alpha+\beta \cdot t+\theta \cdot \text { Vintage }_{t}+\epsilon_{t} \text {, }
$$

where $t$ is a trend variable and Vintage $t$ is a dummy variable equal to one on (1990, 1995, 1996, 1998, 1999, 2000, 2001, 2002, 2003, 2004, 2005, 2006, 2008, 2009, 2010, 2011, 2012), ${ }^{21}$ zero otherwise.

\section{Insert Table 2 here}

In Table 2, we report the results for the fundamental value. This regression explains $93.89 \%$ of the variance in log prices, both the trend and the vintage being positive and highly significant. The fundamental value is the fitted price from Equation (8). Figure 1 plots the evolution of the Liv-Ex Fine Wine Investables Index and its fundamental price over the sample period. Both appear to follow a similar evolution over time.

\footnotetext{
${ }^{20} \mathrm{We}$ consider a range of alternative definitions of the fundamental value. We present the results for these alternative definitions in Section 5.3. Our main results are not altered by these alternative definitions.

${ }^{21}$ These are the vintages that are included in the index (see Appendix A), which, to a varying degree coincide with good vintages.
} 


\section{Insert Figure 1 here}

\section{Empirical Results}

In this section, we report the main results of the paper. We estimate the HAM developed in Section 3 by Quasi-Maximum Likelihood. We estimate this model using all possible combinations of lags $L$, and of different lookback periods $K$, where $K, L=\{1, \ldots, 12\}$ and report the results for the combination that resulted in the highest log-likelihood value, which turns out to be $K=1$ and $L=2$.

\subsection{Estimation Results}

To determine whether there is evidence of heterogeneous beliefs and switching in beliefs, we first estimate a static model, where we impose the restriction of nonswitching, i.e., $\gamma=0$. Subsequently, we estimate the dynamic HAM where $\gamma$ can take any value. The results of both the static and dynamic models are reported in Table 3.

\section{Insert Table 3 here}

The results for the static model, reported in the first column of Table 3, show that there is indeed evidence of both a mean-reverting and an extrapolative term in the returns of the wine index. However, the mean-reverting term, which reflects the degree of mean-reversion according to the fundamentalists is only significant at the $10 \%$ level, and the coefficient is very small in absolute terms, suggesting some evidence of mean- 
reversion. The autoregressive term, on the other hand, is highly significant and positive, suggesting that there is positive persistence in the returns of the wine index. This finding confirms prior results that the wine market is not efficient. Overall, the model produces an adjusted $R^{2}$ just below $10 \%$.

In the second column of Table 3, we report the results for the HAM, where we allow agents to switch between the two different beliefs based on the past forecast accuracy of that belief. If we consider the Likelihood Ratio (LR) statistic of this model versus the static model, we observe that the addition of one parameter, $\gamma$, leads to a highly significant increase in the log-likelihood of the model by 22.41. In addition, the adjusted $\mathrm{R}^{2}$ increases to over $15 \%$ as we move from the static to the dynamic model. This observation provides strong evidence that the HAM can better explain the dynamics of the fine wine index. Furthermore, our finding confirms the existence of both types of beliefs in the market and switching between these beliefs that is driven by the past forecasting performance of these.

When we consider the parameter estimates for the dynamic model, we find strong evidence of mean-reverting behaviour in the price dynamics of wine, with a mean-reversion coefficient of -0.26 . Thus, fundamentalists have a strong belief of meanreversion. However, when we consider the coefficient on the chartist belief, we observe minor changes compared with the static model, the coefficient remains positive and highly significant. Finally, the intensity of choice parameter, $\gamma$, is positive and highly significant. This observation implies that investors do indeed switch between the different beliefs based on the past forecasting performance of the different beliefs and switch towards the belief that had the best forecasting performance in the recent past.

Overall, the results of the HAM show that there is evidence of trading on the basis of both mean-reversion and price extrapolation in this wine index. In addition, the 
model shows that there are shifts in beliefs where investors switch between fundamentalism and chartism based on the past forecast accuracy of the different beliefs and switch to the strategy that yielded the highest forecast accuracy in the recent past.

\subsection{Switching Behaviour}

The estimation results documented in Section 5.1 show that there is strong evidence for the existence of heterogeneous beliefs among fine wine investors and switching between those beliefs based on the past forecasting performance of the different beliefs. In this section, we explore some of the implications of the switching behaviour.

Figure 2 provides a scatterplot that shows the weights on the fundamentalist strategy, $w_{t}^{F}$, versus the relative forecast performance of the fundamentalist vis-à-vis the chartist strategy, that is,

$$
Z_{t}=\frac{Z_{t}^{F}-Z_{t}^{C}}{Z_{t}^{F}+Z_{t}^{C}} .
$$

The graph shows that the function takes on an S-shaped form, where the weight on the fundamentalist strategy gradually increases as the forecast accuracy of the fundamentalist strategy increases. This positive relation between past relative forecast performance of the fundamentalist strategy and the weight on the fundamentalist strategy is driven by the positive value for the intensity of choice parameter, $\gamma$. The Sshaped curve also demonstrates that investors do not switch immediately from one belief to another when its forecast accuracy is better. When the fundamentalist belief is $20 \%$ more accurate than the chartist belief, the weight in the fundamentalist belief is about $80 \%$, whereas when the chartist belief is $20 \%$ more accurate than the fundamentalist belief, the weight on the fundamentalist belief is about $20 \%$. These 
findings illustrate that it takes some time for market participants to change their respective beliefs. This could be due, for instance, to the difficulty for a chartist to fully learn the exact features and working of the wine market and to obtain inside information in a short time span. Finally, irrespective of their belief, market participants appear to decide to trade or shun the market if their respective belief is yielding sub-optimal outcomes. This fact leads to periods in which neither a fundamentalist nor chartist overhang can be detected in the wine market.

\section{Insert Figures 2 and 3 here}

In Figure 3, we provide time series plots of the log difference between the price and the fundamental value of the wine index (left $y$-axis), and the weights on the fundamentalist strategy (right y-axis). First, the weights on the fundamentalist strategy display considerable time variation, with relatively prolonged periods where the market is dominated by the chartist belief which may be explained by the emotional feature of fine wine. This observation is further confirmed in Figure 4, where we plot the histogram of the fundamentalist weights. Second, we observe that there are substantial deviations in the wine index from its fundamental value, which persists over prolonged periods of time. These deviations range from close to $-40 \%$ to up to $80 \%$. Third, we note that the periods where we observe deviations from the fundamental value typically go hand in hand with increased weight on the chartist strategy. This last observation strongly suggests that the deviations from fundamental values are due to the chartist behaviour of wine investors, who, due to their extrapolative behaviour of recent price patterns, continue to push prices away from their fundamental values. ${ }^{22}$

\footnotetext{
${ }^{22}$ Although a comparison between competing bubble-detection approaches is beyond the scope of this paper, we have applied the generalized version of SADF test, GSADF, of Phillips, Shi and Yu (2015)
} 


\section{Insert Figure 4 here}

\subsection{Alternative Fair Value Models}

As mentioned previously, the concept of a fundamental value of wine is rather moot. In this section, we assess the robustness of our results by evaluating the impact of different definitions of fundamental value for our results. Considering alternative specifications is important, as it can affect the degree of switching and the amount of behavioural heterogeneity we observe. Indeed, if our alternative specifications in this section capture the dynamics of the fair value more accurately and align more with the dynamics observed in actual wine values, then we could expect to find less evidence of behavioural heterogeneity, and we could expect the switching parameter, $\gamma$, to decrease in magnitude. Since the fair value of wine is driven by the asset and product cycles, the alternative specifications for the fair value will differ in this regard, i.e. by altering the specification for the price trend (to capture the asset cycle), and by altering the specification of the "vintage" effect (to capture the product cycle).

\section{Insert Table 4 here}

In Table 4, we present the estimation results for HAMs using different definitions of the fundamental value. The specifications of the alternative fundamental models are presented in the first column of Table 4. These alternative specifications differ mainly in how we capture any possible time trends using linear, quadratic and tertiatic functions,

which can detect the presence of multiple bubbles over the Liv-Ex Fine Wine Investables Index. The unreported results confirm the presence of explosive behaviour in wine index, detecting two significant bubbles, from June 1994 to November 1997, and from October 2005 to September 2007. These two bubbles coincide with an average fundamentalist weight of $23.12 \%$ which represents a strong presence of chartists, confirming the main results of our paper. 
and capture the impacts of the vintages in the index in different ways. First, we employ alternative polynomial trends/degrees to capture different definitions of the trend, maintaining the Vintage dummy. Second, we disaggregate the Vintage dummy and use 17 dummies, one for each vintage year. Doing this, we want to give more importance to each vintage year. Third, we change the definition of the vintage component and use a cumulative version of the Vintage dummy, $N$-Vint. As quantity and quality are often negatively correlated, we want to incorporate this in the vintage component not only for the effect of good vintage years but also for the effect of the quantity of good vintage years. Fourth, we re-define the Vintage dummy, focusing only exceptionally good years. Fifth, we remove the Vintage dummy, assuming that all the variation in fundamental price is due to the aging effect component of the index. Finally, we ignore the hedonic pricing approach and model the fundamental value as a moving average of past prices as in Ter Ellen and Zwinkels (2010).

The next two columns report the switching parameters and the LR statistics which compare the static to the dynamic model. Reassuringly, we observe that the main results of our paper do not depend on the choice of fundamental value model. Regardless of the model used, we find positive values for the intensity of choice parameter, $\gamma$, and significant increases in the LR statistic for all specifications. ${ }^{23}$

\footnotetext{
${ }^{23}$ We observe that the switching parameter is insignificant in one case. It is important to points out that the t-statistic for the switching parameter is not well-defined as the parameter enters the model in non-linearly (Teräsvirta, 1994). Boswijk et al. (2007) also report an insignificant switching parameter. However, the Likelihood Ratio test is conclusive in assessing whether the switching model is better than the static model, and in the case of that particular insignificant switching parameter, the LR statistic is significant.
} 


\subsection{Alternative Wine Indices}

In this section, we extend our analysis by considering alternative wine indices. The main index used in our paper so far, the Liv-Ex Fine Wine Investables Index, is comprised only of wines from the Bordeaux region. Wines from this region may be more prone to bubble-like behaviour and chartism, as they attract more speculative investors and inexperienced buyers. Wines from other regions may attract more knowledgeable buyers such as collectors and we could thus expect to see different results.

We apply the HAM to alternative wine indices provided by Liv-Ex. These indices include and are referred to by Liv-ex as the Bordeaux Legends 50 (a selection of 50 Bordeaux wines from exceptional older vintages, dating back to 1982), the Champagne 50 (the most recent physical vintages for twelve Champagnes), the Rhone 100 (the ten most recent physical vintages for five Southern and five Northern Rhone wines), the Italy 100 (the ten most recent physical vintages for the five 'Super Tuscans' and five other leading Italian producers), the Rest of the World 50 (the ten most recent physical vintages for five wines from Spain, Portugal, the USA, and Australia) and the Burgundy 150 (the ten most recent physical vintages for 15 white and red Burgundy, including six Domaine Romanée Conti labels). The sample period for these indices ranges from December 2003 until October 2016.

To be consistent across the different wine indices and provide comparable results, we make use of four fundamental prices that do not include vintage dummies, i.e., only variations of the aging effect and moving average are included. For comparison, we also report the results for the Liv-Ex Fine Wine Investables Index for the sample after December 2003. Table 5 reports the results for the different indices, 
where we report the LR statistics that compare the switching (dynamic) model with the non-switching (static) model.

\section{Insert Table 5 here}

The first row reports the results for the Liv-Ex Fine Wine Investables Index for the common sample period (from December 2003 to October 2016). The Liv-Ex Fine Wine Investables Index presents evidence of both fundamentalist and chartist beliefs with switching among both from December 2003, confirming the results of the full sample. For each of the different fundamental prices, the Bordeaux Legends 50, Rest of the World 50 and Burgundy 150 present evidence of both fundamentalist and chartist beliefs with switching between these beliefs. However, we find no evidence of switching behaviour for the Champagne 50, Rhone 100 and Italy 100 wine indices. We attribute the stronger switching behaviour in the Investables index (and the Bordeaux Legends 50 and Bugundy 150 indices) to the presence of a more heterogeneous clientele for these wines including collectors, speculative investors or new customers from the Asian markets. The other regions, on the other hand, have been less used by investors or exposed to investments by new clients. These regions therefore show a more homogenous clientele, possibly mainly European and American collectors and wine connoisseurs, and thus less evidence of heterogeneity and switching behaviour.

\section{Conclusions}

The main focus of this paper is to examine the dynamics of the fine wine market, and assess whether there is evidence of behavioural heterogeneity in this market. To 
examine this, we introduce a heterogeneous agent model, HAM, to explain the dynamics of the Liv-Ex Fine Wine Investables Index. The results of our model show evidence of the existence of both fundamentalists - those who trade on mean-reversion towards a long-run fundamental or intrinsic value - and chartists - those who extrapolate recently observed price trends - in this market. Moreover, we document that investors switch between fundamentalist and chartist strategies, based on the strategy that has been the most accurate in forecasting prices in the recent past. This switching behaviour can explain the bubbles and crashes (i.e. large price deviations from intrinsic values) that are observed in this wine index. Specifically, we document that any large positive or negative deviation from their fair value coincides with the majority of investors trading on the basis of a chartist belief, suggesting that return-chasing behaviour of investors can explain bubble-like behaviour in fine wine prices. Our results are robust to alternative definitions of the fundamental or fair value of wine. We further demonstrate that the most investable wines in the Liv-Ex Fine Wine Investables indices are most prone to chartism and switching behaviour, a finding that we attribute to these wines being most susceptible to speculative trading. Overall, we find strong evidence that a HAM can explain the dynamics of the fine wine market well. 


\section{References}

Adämmer, P., and Bohl, M.T. (2015). Speculative Bubbles in Agricultural Prices. The Quarterly Review of Economics and Finance, 55, 67-76.

Ashenfelter, O. (2010). Predicting the Quality and Prices of Bordeaux Wine. Journal of Wine Economics, 5(1), 40-52.

Ashenfelter, O., Ashmore, D., and Lalonde, R. (1995). Bordeaux Wine Vintage Quality and the Weather. Chance, 8(4), 7-14.

Baur, D.G, and Glover, K.J. (2014). Heterogeneous Expectations in the Gold Market: Specification and Estimation. Journal of Economic Dynamics and Control, 40, 116133.

Boswijk, H. P., Hommes, C. H., and Manzan, S. (2007). Behavioral Heterogeneity in Stock Prices. Journal of Economic Dynamics and Control, 31(6), 1938-1970.

Bouri, E., Chang, T., and Gupta, R. (2016). Testing the Efficiency of the Wine Market Using Unit Root Tests with Sharp and Smooth Breaks. Working paper.

Brock, W. A., and Hommes, C. H. (1997). A Rational Route to Randomness. Econometrica: Journal of the Econometric Society, 65(5), 1059-1095.

Brock, W. A., and Hommes, C. H. (1998). Heterogeneous Beliefs and Routes to Chaos in a Simple Asset Pricing Model. Journal of Economic Dynamics and Control, 22(8), 1235-1274.

Brooks, C., Prokopczuk, M., and Wu, Y. (2015). Booms and Busts in Commodity Markets: Bubbles or Fundamentals? The Journal of Futures Markets, 35(10), 916-938.

Burton, B. J., and Jacobsen, J. P. (2001). The Rate of Return on Investment in Wine. Economic Inquiry, 39(3), 337-350.

Campbell, R. (2008). Art as a Financial Investment. Journal of Alternative Investments, 10(4), 64-81.

Cardebat; J-M. and Figuet, J-M. (2004). What Explains Bordeaux Wine Prices?. Applied Economics Letters, 11(5), 293-296.

Cardebat, J.-M., Faye, B., Le Fur, E., and Masset, P. (2016), The Fine Wine Price: Product Heterogeneity vs. Heterogeneous Agents, Working Paper.

Cardebat, J., Faye, B., Le Fur, E., and Storchmann, K. (2017). The Law of One Price? Price Dispersion on the Auction Market for Fine Wine. Journal of Wine Economics, 12(3), 302-331.

Cardebat, J.-M., Figuet, J.-M., and Paroissien, E. (2014). Expert Opinion and Bordeaux Wine Prices: An Attempt to Correct Biases in Subjective Judgments. Journal of Wine Economics, 9(3), 282-303. 
Cevik, S., and Sedik, T. S. (2014). A Barrel of Oil or a Bottle of Wine: How Do Global Growth Dynamics Affect Commodity Prices?. Journal of Wine Economics, 9(01), 3450 .

Chen, S.-H., Chang, C.-L., and Du, Y.-R. (2012). Agent-Based Economic Models and Econometrics. Knowledge Engineering Review, 27(2), 187-219.

Coslor, E., and Spaenjers, C. (2016). Organizational and Epistemic Change: The Growth of the Art Investment Field. Accounting, Organizations and Society, 55, 48-62.

Czupryna, M., and Oleksy, P. (2015). Rational Speculative Bubbles in the Fine Wine Investment Market. Kwartalnik Kolegium Ekonomiczno-Społecznego Studia $i$ Prace/Szkoła Główna Handlowa(3, t. 3 Rynek kapitałowy), 159-172.

Danner, L., Ristic, R., Johnson, T., Meiselman, H., Hoek, A., Jeffery, D., Bastian, S. (2016). Context and wine quality effects on consumers' mood, emotions, liking and willingness to pay for Australian Shiraz wines. Food Research International, 89, 254265.

De Grauwe, P., and Grimaldi, M. (2005a). The Exchange Rate and its Fundamentals in a Complex World. Review of International Economics, 13(3), 549-575.

De Grauwe, P., and Grimaldi, M. (2005b). Heterogeneity of Agents, Transactions Costs and the Exchange Rate. Journal of Economic Dynamics and Control, 29(4), 691-719.

De Grauwe, P., and Grimaldi, M. (2006). Exchange Rate Puzzles: A Tale of Switching Attractors. European Economic Review, 50(1), 1-33.

Di Vittorio, A., and Ginsburgh, V. (1996). Pricing Red Wines of Medoc Vintages from 1949 to 1989 at Christie’s Auctions. Journal de la Société Statistique de Paris, 137(1), 19-49.

Dimson, E., and Spaenjers, C. (2011). Ex post: The investment performance of collectible stamps. Journal of Financial Economics, 100(2), 443-458.

Dimson, E. and Spaenjers, C. (2014). Investing in Emotional Assets. Financial Analysts Journal, 70(2), 18-22.

Dimson, E., Rousseau, P. L., and Spaenjers, C. (2015). The Price of Wine. Journal of Financial Economics, 118(2), 431-449.

Erdős, P., and Ormos, M. (2013). Components of Investment Grade Wine Prices. Journal of Wine Research, 24(3), 227-247.

Etienne, X.L., Irwin, S.H., Garcia, P. (2014). Bubbles in Food Commodity Markets: Four Decades of Evidence. Journal of International Money and Finance, 42, 129-155.

Faye, B., Le Fur, E., and Prat, S. (2015). Dynamics of Fine Wine and Asset Prices: Evidence from Short-and Long-Run Co-Movements. Applied Economics, 47(29), 30593077. 
Figuerola-Ferretti, I., Gilbert, C.L., and Mccrorie, J.T. (2015). Testing For Mild Explosivity And Bubbles In Lme Non-Ferrous Metals Prices. Journal of Time Series Analysis, 36, 763-782.

Gergaud, O. and Ginsburgh, V. (2008). Natural Endowments, Production Technologies and the Quality of Wines in Bordeaux. Does Terroir Matter?. The Economic Journal, 118, F142-F157.

Gilbert, C. (2010). Speculative Influences on Commodity Futures Prices 2006-2008. Discussion Papers no. 197. New York: United Nations Conference on Trade and Development (UNCTAD).

Häberle, R., and Masset, P., (2016). Segmentation and Price Dynamics on an Illiquid Market: The Tale of a Heterogeneous Wine Cellar, Working Paper.

Hadj Ali, H. and Nauges, C. (2007). The Pricing of Experience Goods: The Example of en primeur Wine. American Journal of Agricultural Economics, 89(1), 91-103.

Hiraki, T., Ito, A., Spieth, D. A., and Takezawa, N. (2009). How did Japanese investments influence international art prices?. Journal of Financial and Quantitative Analysis, 44(06), 1489-1514.

Jaeger, D. A., and Storchmann, K. (2011). Wine Retail Price Dispersion in the United States: Searching for Expensive Wines? American Economic Review, 101(3), 136-141.

Jiao, L. (2017). Macroeconomic Determinants of Wine Prices. International Journal of Wine Business Research, 29(3), 234-250.

Jovanovic, B. (2013). The 2012 Lawrence R. Klein Lecture: Bubbles in Prices of Exhaustible Resources. International Economic Review, 54(1), 1-34.

Knight Frank (2016). The Wealth Report. https://www.knightfrank.com/wealthreport

Korteweg, A., Kräussl, R. and Verwijmeren, P. (2015). Does it Pay to Invest in Art? A Selection-Corrected Returns Perspective. Review of Financial Studies, 29(4), 10071038.

Kouwenberg, R., and Zwinkels, R. (2014). Forecasting the US Housing Market. International Journal of Forecasting, 30(3), 415-425.

Kräussl, R., Lehnert, T., and Martelin, N. (2016). Is There a Bubble in the Art Market? Journal of Empirical Finance, 35, 99-109.

Lucey, B. M., and Devine, L. (2015). Was Wine a Premier Cru Investment? Research in International Business and Finance, 34, 33-51.

Manski, C. F., and McFadden, D. (1981). Structural Analysis of Discrete Data with Econometric Applications: MIT Press Cambridge, MA. 
Martin, S. G. (2016). The Road Less Traveled: The Case for Collectible Automobiles as an Asset Class. Journal of Wealth Management, 19(3), 131-139.

Masset, P., and Henderson, C. (2010). Wine as an Alternative Asset Class. Journal of Wine Economics, 5(1), 87-118.

Masset, P. and Weisskopf, J.-P. (2018a). Raise your Glass: Wine Investment and the Financial Crisis. In: O. Ashenfelter et al. (Eds.) Handbook of the Economics of Wine. Singapore: World Scientific Publishing.

Masset, P., and Weisskopf, J. P. (2018b). Wine Indices in Practice: Nicely Labeled but Slightly Corked. Economic Modelling, 68, 555-569.

Masset, P., and Weisskopf, J.-P. (2016). A Study of the Performance of Fine Wine on the Swiss Market. International Journal of Entrepreneurship and Small Business, 29(4), 566-582.

Masset, P., Weisskopf, J.-P., Faye, B., and Le Fur, E. (2016). Red Obsession: The Ascent of Fine Wine in China. Emerging Markets Review, 29, 200-225.

Menkhoff, L., Rebitzky, R. R. and Schröder, M. (2009). Heterogeneity in exchange rate expectations: Evidence on the chartist-fundamentalist approach. Journal of Economic Behavior \& Organization, 70(1-2), 241-252.

Mitchell, R. (2012). Profits or Pleasure? Exploring the Motivation behind Treasure Trends, Barclays Bank Wealth Insights 15.

Oczkowski, E. and Doucouliagos, H. (2014). Wine Prices and Quality Ratings: A MetaRegression Analysis. American Journal of Agricultural Economics, 97(1), 103-121.

Penasse, J. and Renneboog, L. (2017). Speculative Trading and Bubbles: Evidence from the Art Market, Working Paper.

Phillips, P.C.B., Wu, Y., and Yu, J. (2011). Explosive Behaviour in the 1990s: When did Exuberance Escalate Asset Values? International Economic Review, 52 (1), 201226.

Phillips, P.C.B., Shi, S., and Yu, J. (2015). Testing for Multiple Bubbles: Historical Episodes of Exuberance and Collapse in the S\&P500. International Economic Review, 56 (4), 1043-1078.

Qiao, Z., and Chu, P. K. K. (2014). Does Fine Wine Price Contain Useful Information to Forecast GDP? Evidence from Major Developed Countries. Economic Modelling, 38, 75-79.

Renneboog, L. and Spaenjers, C. (2013). Buying Beauty: On Prices and Returns in the Art Market. Management Science, 59(1), 36-53.

Robinson, J. (1998). Confessions of a Wine Lover: Penguin. 
Rosen, S. (1974). Hedonic Prices and Implicit Markets: Product Differentiation in Pure Competition. Journal of Political Economy, 82(1), 34-55.

Sanning, L. W., Shaffer, S., and Sharratt, J. M. (2008). Bordeaux Wine as a Financial Investment. Journal of Wine Economics, 3(1), 51-71.

Serdarevic, M. (2012, May 18, 2012). Is the Lafite Bubble About to Pop? FT Alphaville.

Storchmann, K. (2012). Wine Economics. Journal of Wine Economics, 7(1), 1-33.

Ter Ellen, S., and Zwinkels, R. C. (2010). Oil Price Dynamics: A Behavioral Finance Approach with Heterogeneous Agents. Energy Economics, 32(6), 1427-1434.

Teräsvirta, T. (1994). Specification, Estimation, and Evaluation of Smooth Transition Autoregressive Models. Journal of the American Statistical Association, 89(425), 208218.

Tsvetanov, D., Coakley, J., and Kellard, N. (2016). Bubbling Over! The Behavior of Long-Dated Oil Futures Prices. Journal of Empirical Finance, 38, 516-533.

van Norden, S., and Schaller, H. (1993). The Predictability of Stock Market Regime: Evidence from the Toronto Stock Exchange. Review of Economics and Statistics, 75, 505-10.

Veld, C. and Veld-Merkoulova, Y.V. (2007). Portfolio Diversification Benefits of Investing in Stamps. Journal of Alternative Investments, 10(1), 56-61.

Westerhoff, F. H. and Reitz, S. (2003). Nonlinearities and Cyclical Behavior: The Role of Chartists and Fundamentalists. Studies in Nonlinear Dynamics \& Econometrics, 7(4).

Worthington, A.C. and Higgs, H. (2004). Art as an Investment: Risk, Return and Portfolio Diversification in Major Painting Markets. Accounting \& Finance, 44(2), 257271.

Zhou, W.X., and Sornette, D. (2009). A Case Study of Speculative Financial Bubbles in the South African Stock Market 2003-2006. Physica A: Statistical Mechanics and its Applications, 388, 869-880.

Zhang, Y. J., and Yao, T. (2016). Interpreting the Movement of Oil Prices: Driven by Fundamentals or Bubbles? Economic Modelling, 55, 226-240. 
Table 1. Summary statistics

\begin{tabular}{lrr}
\hline \multicolumn{3}{c}{ Wine Index } \\
\hline & Levels & Returns \\
Mean (p.a.) & 134.90 & $10.30 \%$ \\
Std. Deviation (p.a.) & 103.35 & $10.44 \%$ \\
Max & 369.81 & $22.04 \%$ \\
Min & 16.54 & $-13.73 \%$ \\
Skewness & 0.56 & 1.75 \\
Excess Kurtosis & -1.06 & 14.64 \\
JB-test & $34.60 * * *$ & $3255.35^{* * *}$ \\
$\rho(1)$ & $0.99 * * *$ & $0.26 * * *$ \\
Observations & 346 & 345 \\
\hline
\end{tabular}

Note: This table reports summary statistics on the wine index data used in this paper in levels and log returns over the period January 1988 to October 2016. We report annualized averages and standard deviations, and monthly statistics on minimum, maximum, skewness and kurtosis. JB-test is the JarqueBera test for Normality which is asymptotically distributed as a $\chi^{2}$ with two degrees of freedom, and $\rho(1)$ is the first-order autocorrelation of the series which is asymptotically distributed as $N(0,1 / \sqrt{T})$. *** indicates significance at the $1 \%$ level. 
Table 2. OLS regression for fundamental prices.

\begin{tabular}{lcr}
\hline \multicolumn{3}{c}{ Fundamental Equation: } \\
\hline & Coeff. & t-NW \\
& & \\
Constant & $2.744 * * *$ & $(39.31)$ \\
$t$ & $0.009 * * *$ & $(34.33)$ \\
Vintage & $0.273 * * *$ & $(4.27)$ \\
& & \\
Adj-R ${ }^{2}$ & & $93.89 \%$ \\
\hline
\end{tabular}

Note: This table reports the OLS results for the Equation 8. Adj- $\mathrm{R}^{2}$ is the adjusted $\mathrm{R}^{2}$ of the model. Vintage is a dummy variable equal 1 on (1990, 1995, 1996, 1998, 1999, 2000, 2001, 2002, 2003, 2004, 2005, 2006, 2008, 2009, 2010, 2011, 2012), zero otherwise. We report Newey-West corrected t-statistics in parentheses and indicate the significance at the $1 \%$ level by ***. 
Table 3. HAM regression Results

\begin{tabular}{lrrrr}
\hline & \multicolumn{2}{c}{ Static } & \multicolumn{2}{c}{ Dynamic } \\
\cline { 2 - 5 } & coeff & t-NW & coeff & t-NW \\
$c$ & $0.0054^{* * *}$ & $(2.95)$ & $0.0035^{* *}$ & $(2.39)$ \\
$\alpha$ & $-0.0252^{*}$ & $(-1.77)$ & $-0.2638^{* * *}$ & $(-7.52)$ \\
$\beta$ & $0.3825^{* * *}$ & $(4.41)$ & $0.3379 * * *$ & $(11.22)$ \\
$\gamma$ & & & $7.2149 * * *$ & $(4.71)$ \\
Adj-R ${ }^{2}$ & & $9.65 \%$ & & $15.38 \%$ \\
LL & & 728.48 & & 739.68 \\
LR-stat & & & & $22.405^{* * *}$ \\
\hline
\end{tabular}

Note: This table reports the estimation results for the heterogeneous agent model derived in Section 3. Specifically, we estimate the model

$$
\begin{aligned}
& R_{t+1}=c+w_{t}^{F}\left(\alpha\left(P_{t}-V_{t}\right)\right)+\left(1-w_{t}^{F}\right)\left(\beta \sum_{l=1}^{L}\left(R_{t-l+1}\right)\right)+\varepsilon_{t+1} \\
& w_{t}^{F}=\left[1+\exp \left(\gamma\left\{\frac{z_{t}^{F}-z_{t}^{C}}{z_{t}^{F}+z_{t}^{C}}\right\}\right)\right]^{-1} \\
& Z_{t}^{F}=\sum_{k=1}^{K}\left|E_{t-k}^{F}\left(P_{t-k+1}\right)-P_{t-k+1}\right|, \quad Z_{t}^{C}=\sum_{k=1}^{K}\left|E_{t-k}^{C}\left(P_{t-k+1}\right)-P_{t-k+1}\right|
\end{aligned}
$$

The coefficient $\alpha$ captures the degree of mean-reversion towards the fundamental value, $\beta$ captures the degree of persistence in the returns on the Wine index, and $\gamma$ is the intensity of choice parameter, which captures the degree of switching behaviour between the fundamentalist and chartist beliefs. Adj- $\mathrm{R}^{2}$ is the adjusted $\mathrm{R}^{2}$ of the model, LL is the log-likelihood of the model, and LR-stat is the likelihood ratio statistic calculated as twice the difference between the log-likelihood of the dynamic and the static model. We report Newey-West corrected t-statistics in parentheses and indicate the significance at the $10 \%, 5 \%$, and $1 \%$ level by $*, * *$, and $* * *$, respectively. 
Table 4. Robustness HAM regression: Alternative fundamental models

\begin{tabular}{|c|c|c|}
\hline Fundamental Equation & $\gamma$ & LR-stat \\
\hline $\log \left(\right.$ Wine_Index $\left._{t}\right)=\alpha+\beta_{0} \cdot t+\beta_{1} \cdot t^{2}+\theta \cdot$ Vintage $_{t}+\epsilon_{t}$ & $10.61^{* * *}$ & $22.69 * * *$ \\
\hline $\log \left(\right.$ Wine_Index $\left._{t}\right)=\alpha+\beta_{0} \cdot t+\beta_{1} \cdot t^{2}+\beta_{2} \cdot t^{3}+\theta \cdot$ Vintage $_{t}+\epsilon_{t}$ & $6.20 * * *$ & $13.61^{* * *}$ \\
\hline $\log \left(\right.$ Wine_Index $\left._{t}\right)=\alpha+\beta \cdot t+\sum_{y=1989}^{2012} \theta_{y} \cdot V I N T_{-} Y E A R_{y, t}+\epsilon_{t}$ & $1.52 * * *$ & $14.49 * * *$ \\
\hline $\log \left(\right.$ Wine_Index $\left._{t}\right)=\alpha+\beta_{0} \cdot t+\beta_{1} \cdot t^{2}+\sum_{y=1989}^{2012} \theta_{y} \cdot V I N T_{-} Y E A R_{y, t}+\epsilon_{t}$ & $1.40 * * *$ & $10.95^{* * *}$ \\
\hline $\log \left(\right.$ Wine_Index $\left._{t}\right)=\alpha+\beta_{0} \cdot t+\beta_{1} \cdot t^{2}+\beta_{2} \cdot t^{3}+\sum_{y=1989}^{2012} \theta_{y} \cdot V I N T_{-} Y E A R_{y, t}+\epsilon_{t}$ & $2.85 * * *$ & $8.70 * * *$ \\
\hline $\log \left(\right.$ Wine_Index $\left._{t}\right)=\alpha+\beta \cdot t+\theta \cdot N_{-}$Vint $_{t}+\epsilon_{t}$ & 17.49 & $13.57 * * *$ \\
\hline $\log \left(\right.$ Wine_Index $\left._{t}\right)=\alpha+\beta_{0} \cdot t+\beta_{1} \cdot t^{2}+\theta \cdot N_{-}$Vint $_{t}+\epsilon_{t}$ & $10.56^{* * *}$ & $14.45^{* * *}$ \\
\hline $\log \left(\right.$ Wine_Index $\left._{t}\right)=\alpha+\beta_{0} \cdot t+\beta_{1} \cdot t^{2}+\beta_{2} \cdot t^{3}+\theta \cdot N_{-}$Vint $_{t}+\epsilon_{t}$ & $1366.93 * * *$ & $12.49 * * *$ \\
\hline $\log \left(\right.$ Wine_Index $\left._{t}\right)=\alpha+\beta \cdot t+\theta \cdot$ Good_Years $_{t}+\epsilon_{t}$ & $1.50^{* * *}$ & $10.87 * * *$ \\
\hline $\log \left(\right.$ Wine_Index $\left._{t}\right)=\alpha+\beta_{0} \cdot t+\beta_{1} \cdot t^{2}+\theta \cdot$ Good_Years $_{t}+\epsilon_{t}$ & $1.51^{* * *}$ & $10.94 * * *$ \\
\hline $\log \left(\right.$ Wine_Index $\left._{t}\right)=\alpha+\beta_{0} \cdot t+\beta_{1} \cdot t^{2}+\beta_{2} \cdot t^{3}+\theta \cdot$ Good_Years $_{t}+\epsilon_{t}$ & $12.01^{* * *}$ & $19.63 * * *$ \\
\hline $\log \left(\right.$ Wine_Index $\left._{t}\right)=\alpha+\beta \cdot t+\epsilon_{t}$ & $707.03 * * *$ & $17.73 * * *$ \\
\hline $\log \left(\right.$ Wine_Index $\left.x_{t}\right)=\alpha+\beta_{0} \cdot t+\beta_{1} \cdot t^{2}+\epsilon_{t}$ & $10.56^{* * *}$ & $14.92 * * *$ \\
\hline $\log \left(\right.$ Wine_Index $\left.x_{t}\right)=\alpha+\beta_{0} \cdot t+\beta_{1} \cdot t^{2}+\beta_{2} \cdot t^{3}+\epsilon_{t}$ & $1.54^{* * *}$ & $11.28 * * *$ \\
\hline $\log \left(24-\right.$ month Moving average Wine_Index $\left.x_{t}\right)$ & $97.15^{* *}$ & $11.50 * * *$ \\
\hline
\end{tabular}

Note: This Table reports the estimation results for the heterogeneous agent model derived in Section 3 for alternative fundamental models. The coefficient $\gamma$ is the intensity of choice parameter, which captures the degree of switching behaviour between the fundamentalist and chartist beliefs, and LR-stat is the likelihood ratio statistic calculated as twice the difference between the log-likelihood of the dynamic and the static model. We indicate the significance of the Newey-West corrected t-statistics at the $10 \%, 5 \%$, and $1 \%$ level by *, **, and ***, respectively. VINT_YEAR ${ }_{y, t}$ is a yearly dummy, e.g., VINT_YEAR $1990, t$ is a dummy equal one in 1990, and zero otherwise; likewise for (1995, 1996, 1998, 1999, 2000, 2001, 2002, 2003, 2004, 2005, 2006, 2008, 2009, 2010, 2011, 2012). Good_Years $s_{t}$ is a dummy variable equal one in exceptional good years $\{1990,1996,1998,2000,2005,2009,2010\}$; zero otherwise.

$N_{-}$Vint $_{t}$ is the cumulative number of vintages in the portfolio, 


$N_{-V i n t_{t}}=\left\{\begin{array}{rlr}0 & \text { iff } & t<1990 \\ 1 & \text { iff } & 1990 \leq t<1995 \\ 2 & \text { iff } & 1995 \leq t<1996 \\ 3 & \text { iff } & 1996 \leq t<1998 \\ 4 & \text { iff } & 1998 \leq t<1999 \\ 5 & \text { iff } & 1999 \leq t<2000 \\ 6 & \text { iff } & 2000 \leq t<2001 \\ 7 & \text { iff } & 2001 \leq t<2002 \\ 8 & \text { iff } & 2002 \leq t<2003 \\ 9 & \text { iff } & 2003 \leq t<2004 \\ 10 & \text { iff } & 2004 \leq t<2005 \\ 11 & \text { iff } & 2005 \leq t<2006 \\ 12 & \text { iff } & 2006 \leq t<2008 \\ 13 & \text { iff } & 2008 \leq t<2009 \\ 14 & \text { iff } & 2009 \leq t<2010 \\ 15 & \text { iff } & 2010 \leq t<2011 \\ 16 & \text { iff } & 2011 \leq t<2012 \\ 17 & \text { iff } & t \geq 2012\end{array}\right.$


Table 5. Robustness HAM regression: Alternative wine indices

\begin{tabular}{|c|c|c|c|c|c|c|c|c|}
\hline & \multicolumn{2}{|l|}{$\mathrm{I}$} & \multicolumn{2}{|l|}{ II } & \multicolumn{2}{|c|}{ III } & \multicolumn{2}{|c|}{ IV } \\
\hline & LR-stat & $\mathrm{p}$-value & LR-stat & $\mathrm{p}$-value & LR-stat & $\mathrm{p}$-value & LR-stat & p-value \\
\hline Liv-ex Investables & $25.51 * * *$ & 0.0000 & $13.50 * * *$ & 0.0002 & $12.84^{* * *}$ & 0.0003 & $14.33^{* * *}$ & 0.0002 \\
\hline Bordeaux Legends 50 & $21.29 * * *$ & 0.0000 & $5.50 * *$ & 0.0191 & $3.75^{*}$ & 0.0527 & $6.66 * * *$ & 0.0099 \\
\hline Rhone 100 & 1.40 & 0.2362 & 1.54 & 0.2144 & 2.28 & 0.1309 & 0.16 & 0.6893 \\
\hline Italy 100 & 2.43 & 0.1189 & 0.03 & 0.8689 & 1.45 & 0.2289 & 2.33 & 0.1268 \\
\hline
\end{tabular}

Note: This Table reports the estimation results for the heterogeneous agent model derived in Section 3 for alternative Wine Indices using as fundamental models:

I) $\log \left(\right.$ Wine_Index $\left._{t}\right)=\alpha+\beta_{0} \cdot t+\epsilon_{t}$; II $) \log \left(\right.$ Wine_Index $\left._{t}\right)=\alpha+\beta_{0} \cdot t+\beta_{1} \cdot t^{2}+\epsilon_{t}$; III $) \log \left(\right.$ Wine_Index $\left._{t}\right)=\alpha+\beta_{0} \cdot t+\beta_{1} \cdot t^{2}+\beta_{2} \cdot t^{3}+\epsilon_{t}$; and iv $)$ $\log (24$ - month Moving average Wine_Index $)$. The LR-stat is the likelihood ratio statistic calculated as twice the difference between the log-likelihood of the dynamic and the static model. We indicate the significance at the $10 \%, 5 \%$, and $1 \%$ level by *, **, and ${ }^{* * *}$, respectively. 
Figure 1. Liv-ex Fine Wine Investables Index and its fundamental value from January 1988 to October 2016

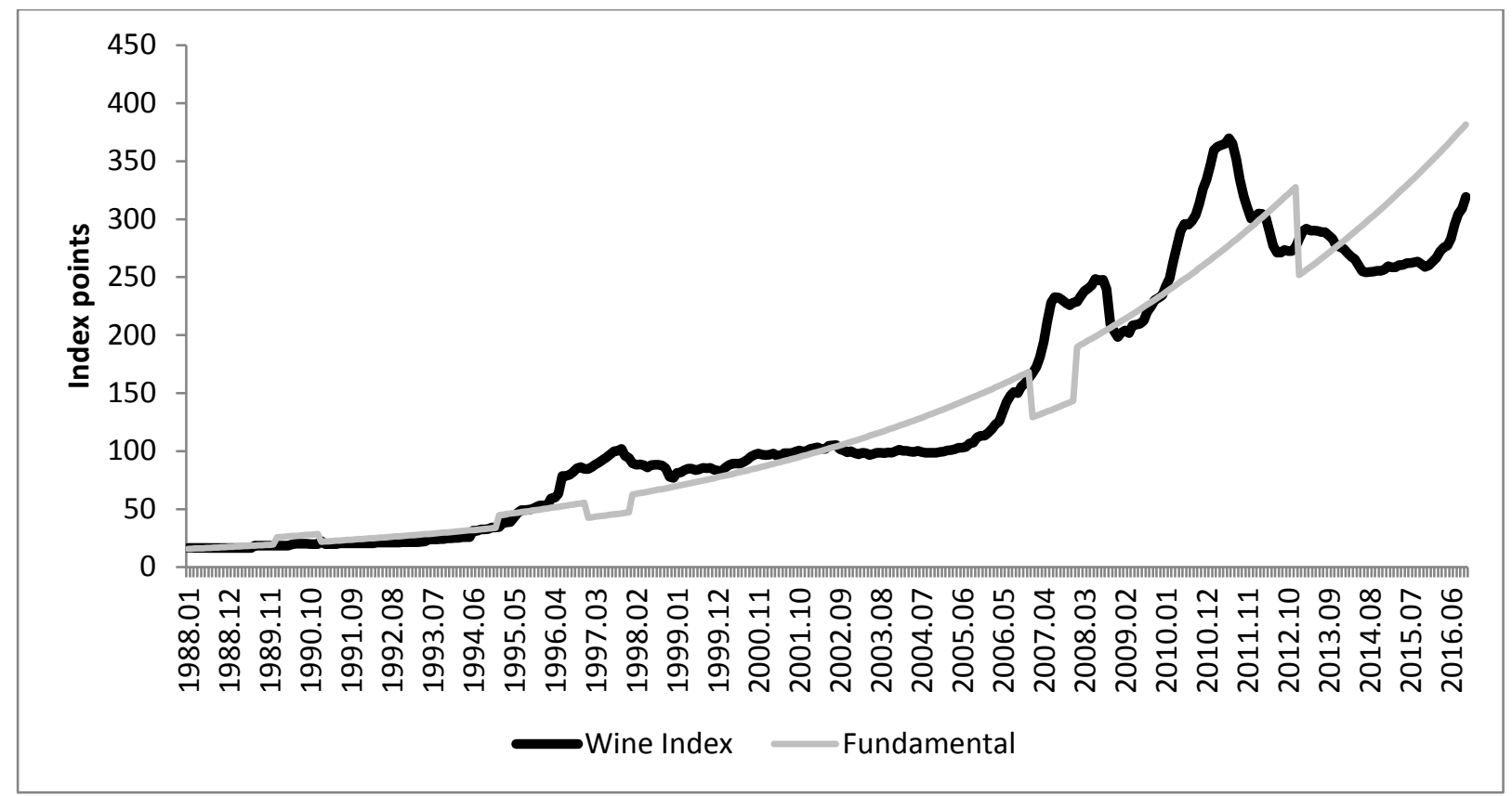

Note: The figure displays the evolution of the Liv-ex Investables index as well as its fundamental value over the entire sample period. 
Figure 2. Fundamentalist weight versus forecast performance

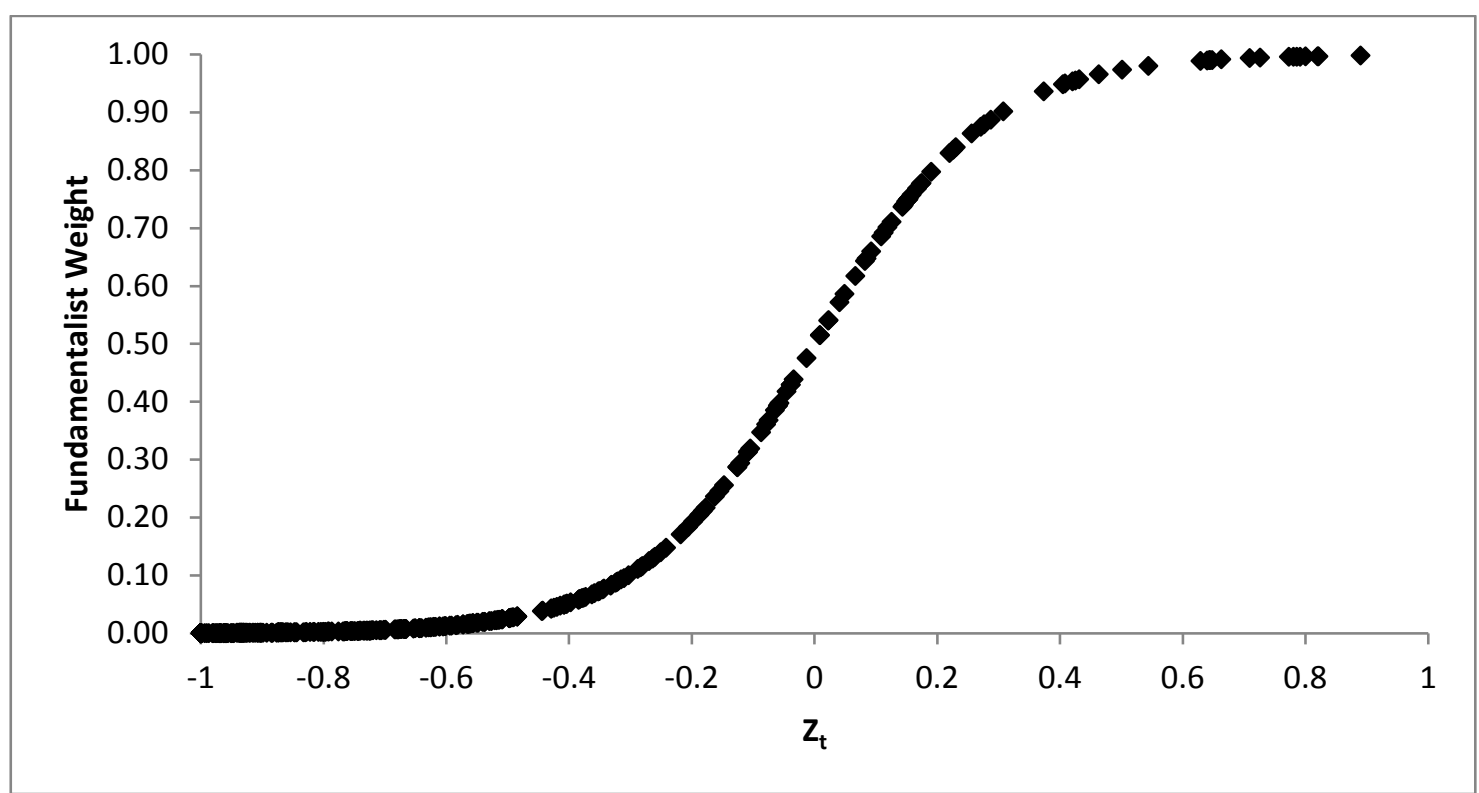

Note: This figure plots the weights allocated to the fundamentalist strategy against the relative forecasting performance of fundamentalist strategy versus the chartist strategy, i.e.,

$$
Z_{t}=\frac{Z_{t}^{F}-Z_{t}^{C}}{Z_{t}^{F}+Z_{t}^{C}}
$$


Figure 3. Fundamentalist weights and deviations from fundamentals.

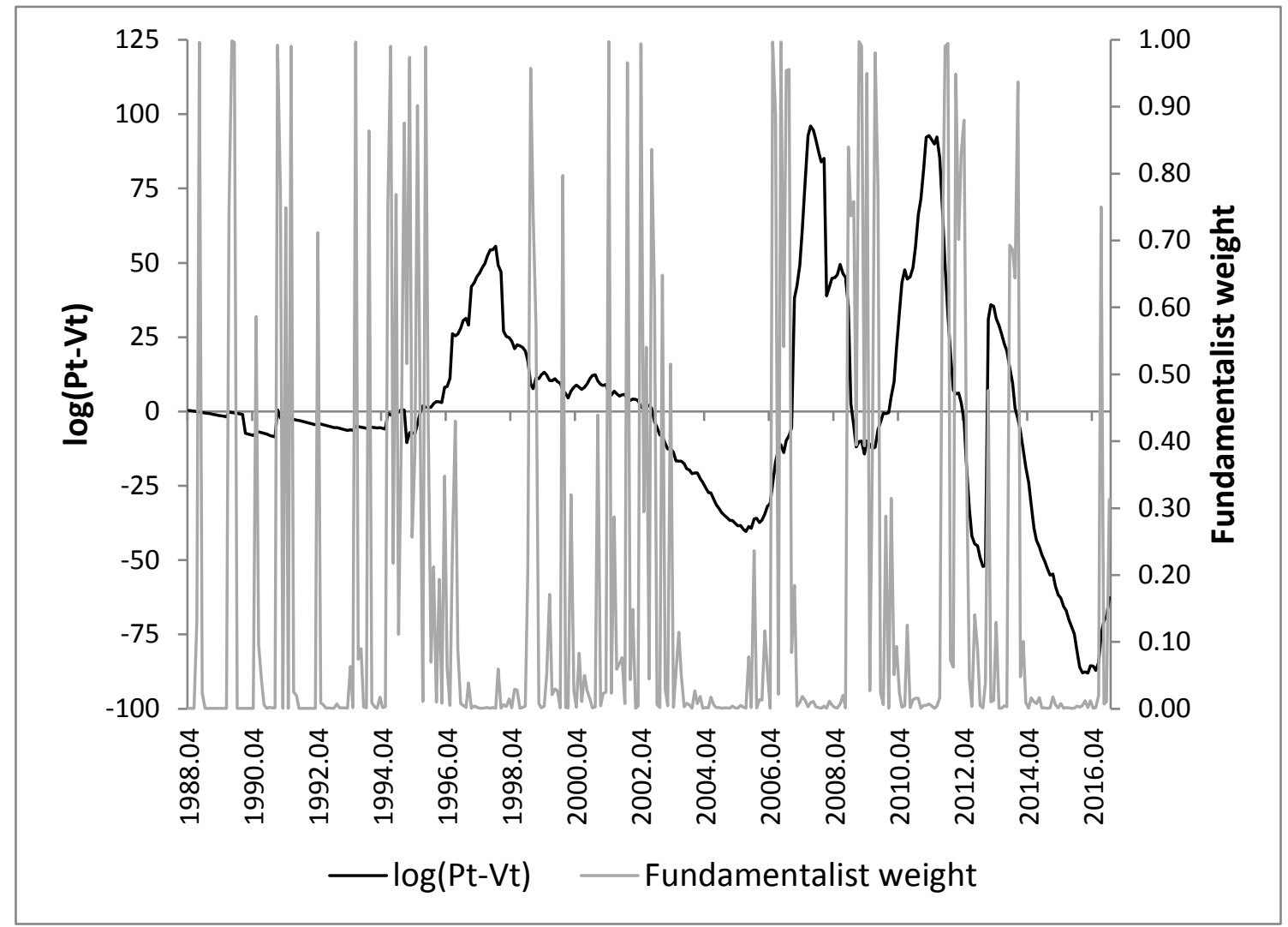

Note: This figure shows the log price deviation between the wine index and the fundamental value, $\log \left(\mathrm{P}_{\mathrm{t}}-\mathrm{V}_{\mathrm{t}}\right)$ (left axis), the weights on the fundamentalist strategy (right axis). 
Figure 4. Histogram of the fundamentalist weights.

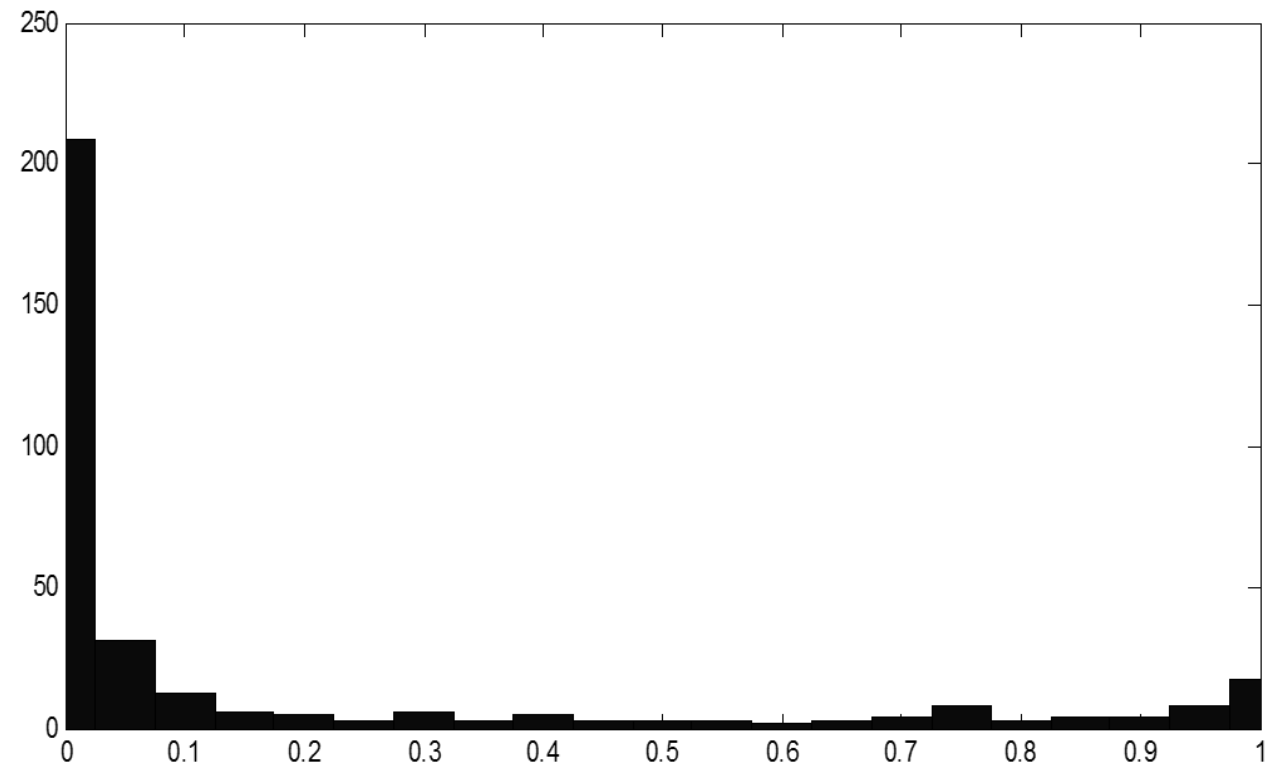

Note: This figure shows the histogram of the weights on the fundamentalist strategy from January 1988 to October 2016. 
Appendix A. Component fine wines and vintages of Liv-ex Fine Wine Investables Index dated on 2015.

\begin{tabular}{|c|c|c|c|c|c|c|c|}
\hline Wine name & Vintage Wine name & Vintage Wine name & Vintage Wine name & Vintage Wine name & Vintage Wine name & Vintage Wine name & Vintage \\
\hline Angelus & 1990 Margaux & 1996 Pavie & 2000 Ausone & 2005 Conseillante & 2008 Petrus & 2009 Haut Brion & 2011 \\
\hline Cheval Blanc & 1990 Montrose & 1996 Petrus & 2000 Cheval Blanc & 2005 Ducru Beaucaillou & 2008 Pichon Baron & 2009 Mission Haut Brion & 2011 \\
\hline Conseillante & 1990 Mouton Rothschild & 1996 Pichon Baron & 2000 Conseillante & 2005 Haut Brion & 2008 Pichon Lalande & 2009 Palmer & 2011 \\
\hline Grand Puy Lacoste & 1990 Pichon Lalande & 1996 Pichon Lalande & 2000 Cos d'Estournel & 2005 Lafite Rothschild & 2008 Pontet Canet & 2009 Pavie & 2011 \\
\hline Haut Brion & 1990 Haut Brion & 1998 Ausone & 2001 Ducru Beaucaillou & 2005 Latour & 2008 Angelus & 2010 Petrus & 2011 \\
\hline Lafite Rothschild & 1990 Lafite Rothschild & 1998 Latour & 2001 Grand Puy Lacoste & 2005 Mission Haut Brion & 2008 Ausone & 2010 Angelus & 2012 \\
\hline Latour & 1990 Mouton Rothschild & 1998 Pavie & 2001 Haut Brion & 2005 Montrose & 2008 Cheval Blanc & 2010 Ausone & 2012 \\
\hline Leoville Las Cases & 1990 Pavie & 1998 Petrus & 2001 Lafite Rothschild & 2005 Pavie & 2008 Conseillante & 2010 Conseillante & 2012 \\
\hline Leoville Poyferre & 1990 Petrus & 1998 Ausone & 2002 Latour & 2005 Petrus & 2008 Cos d'Estournel & 2010 Haut Brion & 2012 \\
\hline Lynch Bages & 1990 Ausone & 1999 Latour & 2002 Leoville Las Cases & 2005 Pichon Baron & 2008 Ducru Beaucaillou & 2010 Margaux & 2012 \\
\hline Margaux & 1990 Lafite Rothschild & 1999 Leoville Las Cases & 2002 Margaux & 2005 Pontet Canet & 2008 Grand Puy Lacoste & 2010 Mission Haut Brion & 2012 \\
\hline Mission Haut Brion & 1990 Palmer & 1999 Angelus & 2003 Mission Haut Brion & 2005 Angelus & 2009 Haut Brion & 2010 Mouton Rothschild & 2012 \\
\hline Montrose & 1990 Pavie & 1999 Ausone & 2003 Montrose & 2005 Ausone & 2009 Lafite Rothschild & 2010 Palmer & 2012 \\
\hline Petrus & 1990 Angelus & 2000 Cos d'Estournel & 2003 Mouton Rothschild & 2005 Cheval Blanc & 2009 Latour & 2010 Pavie & 2012 \\
\hline Pichon Baron & 1990 Ausone & 2000 Haut Brion & 2003 Palmer & 2005 Conseillante & 2009 Leoville Barton & 2010 Petrus & 2012 \\
\hline Angelus & 1995 Cheval Blanc & 2000 Lafite Rothschild & 2003 Pavie & 2005 Cos d'Estournel & 2009 Leoville Las Cases & 2010 & \\
\hline Cos d'Estournel & 1995 Conseillante & 2000 Latour & 2003 Petrus & 2005 Ducru Beaucaillou & 2009 Leoville Poyferre & 2010 & \\
\hline Grand Puy Lacoste & 1995 Ducru Beaucaillou & 2000 Leoville Barton & 2003 Pontet Canet & 2005 Grand Puy Lacoste & 2009 Lynch Bages & 2010 & \\
\hline Haut Brion & 1995 Haut Brion & 2000 Leoville Las Cases & 2003 Angelus & 2006 Haut Brion & 2009 Margaux & 2010 & \\
\hline Lafite Rothschild & 1995 Lafite Rothschild & 2000 Leoville Poyferre & 2003 Ausone & 2006 Lafite Rothschild & 2009 Mission Haut Brion & 2010 & \\
\hline Latour & 1995 Latour & 2000 Margaux & 2003 Cheval Blanc & 2006 Latour & 2009 Montrose & 2010 & \\
\hline Leoville Las Cases & 1995 Leoville Barton & 2000 Montrose & 2003 Haut Brion & 2006 Leoville Las Cases & 2009 Mouton Rothschild & 2010 & \\
\hline Margaux & 1995 Leoville Las Cases & 2000 Pavie & 2003 Lafite Rothschild & 2006 Leoville Poyferre & 2009 Palmer & 2010 & \\
\hline Mouton Rothschild & 1995 Leoville Poyferre & 2000 Pichon Lalande & 2003 Latour & 2006 Lynch Bages & 2009 Pavie & 2010 & \\
\hline Petrus & 1995 Lynch Bages & 2000 Pontet Canet & 2003 Leoville Las Cases & 2006 Margaux & 2009 Petrus & 2010 & \\
\hline Pichon Lalande & 1995 Margaux & 2000 Angelus & 2004 Mouton Rothschild & 2006 Mission Haut Brion & 2009 Pichon Baron & 2010 & \\
\hline Ducru Beaucaillou & 1996 Mission Haut Brion & 2000 Lafite Rothschild & 2004 Pavie & 2006 Montrose & 2009 Pichon Lalande & 2010 & \\
\hline Lafite Rothschild & 1996 Montrose & 2000 Latour & 2004 Pichon Lalande & 2006 Mouton Rothschild & 2009 Pontet Canet & 2010 & \\
\hline Latour & 1996 Mouton Rothschild & 2000 Pavie & 2004 Pontet Canet & 2006 Palmer & 2009 Ausone & 2011 & \\
\hline Leoville Las Cases & 1996 Palmer & 2000 Angelus & 2005 Ausone & 2008 Pavie & 2009 Cheval Blanc & 2011 & \\
\hline
\end{tabular}

